\title{
Eksistensi Ilmu Kanuragan Rajah Pakuwon di Era Globalisasi
}

\author{
Triani Widyanti ${ }^{1}$ Tetep $^{2}$ \\ Institut Pendidikan Indonesia \\ Fakultas Ilmu Sosial Bahasa dan Sastra \\ trianiw@institutpendidikan.ac.id ${ }^{1}$, tetep@institutpendidikan.ac.id ${ }^{2}$
}

\begin{abstract}
This study aims to examine the legends that live among the Sancang Forest community, which is devoted to research on the existence of kanuragan raku pakuwon science. Sancang forests in the South Garut region, save many mystery legends which in turn affect the attitude of life in the surrounding community. The sacred views on the sancang forest and the greatness of their ancestors, namely Prabu Siliwangi, have given birth to attitudes that glorify nature and all its legacy. Various traditional abstinence and belief in extraordinary power for human dignity, born from attitudes and sacred views about the forest and karuhun (ancestors), so that local wisdom emerged in the local community in addressing and preserving the natural environment and all aspects of its ritual. Along with the development of the era in the current era of Globalization, the values of local wisdom in the development of Rajah Pakuwon Kanuragan Science seems to have shifted, but some people still preserve it. This research was conducted using qualitative methods, with a phenomenological approach. Through this approach, all forms of social phenomena that arise in research studies can be exposed to the deeper meaning of a phenomenon, in this case the meaning of a pakuwon-kanuragan science for the people of South Garut.
\end{abstract}

Keyword : Kanuragan Rajah Pakuwon, Sancang Jungle, Local Wisdom, Globalization Era.

Abstrak

Penelitian ini bertujuan untuk mengkaji legenda yang hidup dikalangan masyarakat kawasan Hutan Sancang, yang dikhususkan pada penelitian tentang keberadaan ilmu kanuragan rajah pakuwon. Hutan sancang di wilayah Garut Selatan, menyimpan banyak misteri legenda yang pada gilirannya mempengaruhi sikap hidup masyarakat di sekitarnya. Pandangan-pandangan sakral tentang Hutan sancang serta kebesaran leluhur mereka yakni Prabu Siliwangi, telah melahirkan sikap yang memuliakan alam dan semua peninggalannya. Berbagai pantangan adat serta keyakinan akan kekuatan luar biasa bagi kedigjayaan manusia, lahir dari sikap dan pandangan sakral tentang hutan dan karuhun (leluhur), sehingga muncul kearifan lokal masyarakat setempat dalam menyikapi dan melestarikan lingkungan alam dan segala aspek ritualnya. Seiring dengan perkembangan zaman di era Globalisasi saat ini, nilai-nilai kearifan lokal dalam pengembangan Ilmu Kanuragan Rajah Pakuwon nampaknya mengalami pergeseran, akan tetapi sebagian masyarakat masih melestarikannya. Penelitian ini dilakukan menggunakan metode kualitatif, dengan pendekatan fenomenologi. Melalui pendekatan ini, segala bentuk fenomena sosial yang muncul dalam kajian penelitian dapat dipaparkan hingga menyentuh kepada pemaknaan yang lebih dalam pada suatu fenomena, dalam hal ini adalah kebermaknaan sebuah ilmu kanuragan rajah pakuwon bagi masyarakat Garut Selatan.

Kata Kunci : Ilmu Kanuragan Rajah Pakuwon, Hutan Sancang, Kearifan Lokal, Era Globalisasi

\section{PENDAHULUAN}

Dalam studi kebudayaan, pada hakikatnya legenda menempati posisi yang cukup penting terutama dalam aspek fungsi dan perannya dalam kehidupan masyarakat. Melalui pengkajian terhadap legenda, akan diperoleh informasi atau gambaran yang komprehensif mengenai kondisi sosial budaya suatu masyarakat terkait dengan sikap dan pandangan, serta perilaku ritualnya.

Masyarakat Sunda di wilayah Pameungpeuk-Garut Selatan pada umumnya, memiliki ikatan psikologis yang cukup kuat dengan legenda Sancang dan cerita Sri Baduga Maha Raja atau Prabu Siliwangi melalui situs dan cagar budaya yang terdapat di wilayah tersebut. Berbagai legenda maupun bukti-bukti sejarah tentang keberadaan Sancang sebagai tempat pelarian terakhir Prabu Siliwangi akibat kejaran putranya prabu Kiansantang melekat cukup kuat dalam tradisi budaya masyarakat setempat. Munculnya konsep leuweung larangan (Hutan Terlarang) yang kemudian sangat di jaga oleh penduduk turut pula memunculkan keyakinan lain tentang sebuah filosofi ilmu yang bersifat supranatural yang sering disebut dengan istilah ilmu Kanuragan. 
Secara umum, ilmu kanuragan cenderung tidak dapat dilepaskan dari kehidupan masyarakat Jawa. Pada masa lalu, berbagai jenis ilmu kanuragan turut mewarnai nilai-nilai budaya dalam suatu kelompok masyarakat, baik itu masyarakat pedalaman maupun masyarakat di pesisir pantai. Setiap keluarga bahkan mungkin setiap orang, seolah-olah diwajibkan untuk memiliki dasar ilmu kanuragan. Hal ini terutama terjadi dalam kurun waktu antara masa pra penjajahan, masa penjajahan, masa awal kemerdekaan, dan masa munculnya berbagai bentuk aksi pemberontakan.

Pada dasarnya setiap daerah memiliki ciri khas atau karakteristik ilmu kanuragan. Ilmu-ilmu tersebut diyakini memiliki keunggulan dan kehebatan yang berbeda-beda, akan tetapi terdapat kesamaan dalam memperoleh hasilnya yaitu bahwa orang yang mempelajari ilmu kanuragan akan memiliki kekebalan terhadap segala sesuatu yang membahayakan. Apabila menilik pada kurun waktu perkembangan ilmu kanuragan, maka nampaknya tujuan dari mempelajari ilmu kanuragan adalah untuk membentengi diri dan keluarga dari ancaman bahaya yang rentan akan menyerang baik selama penjajahan maupun pada masa awal kemerdekaan. Salah satu ilmu kanuragan yang cukup terkenal dan diminati oleh masyarakat Sunda adalah Ilmu KanuraganRajah Pakuwon. Ilmu Kanuragan Rajah Pakuwon merupakan ilmu kanuragan yang menjadi ciri khas dari wilayah Sancang Garut. Meski demikian, ilmu ini dapat diperoleh di wilayah lain diluar Sancang, dengan syarat-syarat tertentu.

Diskursus tentang ilmu kanuragan Rajah Pakuwon Sancang dalam konteks era masa lalu maupun masa kini sepertinya menjadi tema yang menarik untuk didiskusikan. Hal yang menjadi daya tarik adalah perspektif makna dan peran serta kiprah para pengguna Ilmu Kanuragan selama ini. Berbagai fakta historis mencatat bahwa llmu kanuragan Rajah Pakuwon dengan berbagai simbolnya telah menjadi bagian yang tidak dapat dipisahkan dengan kehidupan masyarakat Sancang Pameungpeuk Garut, baik pada masa silam maupun masa kini.

Akan tetapi seiring dengan perkembangan ilmu pengetahuan dan teknologi yang semakin pesat di era Globalisasi memunculkan dampak terjadinya perubahan sosial dan budaya masyarakat di hampir setiap wilayah, tidak terkecuali masyarakat sekitar Sancang Garut. Kemudahan mengakses berbagai informasi dari penggunaan media massa online maupun media sosial pada gilirannya telah turut pula merubah pandangan masyarakat terhadap arti dari nilai-nilai kearifan lokal. Hal tersebut nampaknya juga berdampak pada keberadaan Ilmu Kanuragan Rajah Pakuwon. Berdasarkan pemaparan tersebut, penelitian ini bertujuan untuk mengkaji lebih dalam mengenai eksistensi ilmu kanuragan rajah pakuwon yang berkembang di wilayah Pameungpeuk Garut Selatan ditengah gempuran era globalisasi dewasa ini.

\section{KAJIAN PUSTAKA}

\section{Kajian Lokal Wisdom tentang Kanuragan di Era Globalisasi}

\section{- Kearifan Lokal}

Kearifan lokal dapat diartikan sebagai kearifan dalam kebudayaan tradisional suku-suku bangsa. Setiap suku bangsa memiliki nilai-nilai kearifan lokal, baik yang tumbuh dari budaya tradisional setempat, sebagai hasil adopsi budaya dari luar (termasuk adopsi nilai ajaran Agama) maupun sebagai hasil adaptasi budaya dari luar terhadap tradisi setempat (Sedyawati, 2006). Kearifan lokal merupakan entitas yang sangat menentukan harkat dan martabat manusia dalam komunitasnya (Geertz, 2007). Kearifan lokal (local wisdom atau local genius) merupakan pemikiran atau ide setempat (lokal) yang mengandung nilai-nilai bijaksana, kreatif, kebaikan, yang terinternalisasi secara turun temurun (mentradisi). Kearifan lokal adalah identitas atau kepribadian budaya sebuah bangsa yang menyebabkan bangsa tersebut mampu menyerap, bahkan mengolah kebudayaan yang berasal dari luar/bangsa lai menjadi watak dan kemampuan sendiri Wibowo (2015:17). Identitas dan Kepribadian tersebut tentunya menyesuaikan dengan pandangan hidup masyarakat sekitar agar tidak terjadi pergesaran nilai-nilai. Kearifan lokal adalah salah satu sarana dalam mengolah kebudayaan dan mempertahankan diri dari kebudayaan asing yang tidak baik. Kearifan lokal adalah pandangan hidup dan ilmu pengetahuan serta berbagai strategi kehidupan yang berwujud aktivitas yang dilakukan oleh masyarakat lokal dalam menjawab 
berbagai masalah dalam pemenuhan kebutuhan mereka. Dalam bahasa asing sering juga dikonsepsikan sebagai kebijakan setempat local wisdom atau pengetahuan setempat "local knowledge" atau kecerdasan setempat local genious (Fajarini ,2014:123). Hal senada juga diungkapkan oleh Alfian (2013: 428) Kearifan lokal diartikan sebagai pandangan hidup dan pengetahuan serta sebagai strategi kehidupan yang berwujud aktifitas yang dilakukan oleh masyarakat lokal dalam memenuhi kebutuhan mereka. Selanjutnya Istiawati (2016:5) berpandangan bahwa kearifan lokal merupakan cara orang bersikap dan bertindak dalam menanggapi perubahan dalam lingkungan fisik dan budaya. Suatu gagasan konseptual yang hidup dalam masyarakat, tumbuh dan berkembang secara terus-menerus dalam kesadaran masyarakat dari yang sifatnya berkaitan dengan kehidupan yang sakral sampai dengan yang profan (bagian keseharian dari hidup dan sifatnya biasa-biasa saja). Kearifan lokal atau local wisdom dapat dipahami sebagai gagasan-gagasan setempat local yang bersifat bijaksana, penuh kearifan, bernilai baik, yang tertanam dan diikuti oleh anggota masyarakatnya.

\section{- Era Globalisasi}

Para pemikir barat menyatakan bahwa globalisasi adalah sebagai suatu proses kehidupan yang serba luas dan meliputi segala aspek kehidupan, seperti politik, ideologi, sosial budaya,ekonomi yang dapat dirasakan oleh seluruh umat manusia di dunia (tanpa batas) (Syarbaini, 2015: 262). Selain itu, Giddens (1991: 64) mengartikan globalisasi sebagai intensifikasi hubungan sosial dunia yang menghubungkan tempat-tempat jauh sehingga peristiwa disuatu tempat dapat dipengaruhi oleh peristiwa yang terjadi di tempat lain sekian kilometer jauhnya dan sebaliknya. Globalisasi juga diartikan sebagai proyek negara-negara Adikuasa untuk menjalankan perekonomian kapitalis. Negara-negara yang kuat dan kaya akan mengendalikan ekonomi dunia dan negara-negara yang kecil makin tidak mampu bersaing. Sebab itu globalisasi cenderung berpengaruh terhadap perekonomian dunia bahkan berpengaruh terhadap aspek kehidupan lain seperti agama dan budaya. Sehingga Globalisasi sering diartikan sebagai proses yang menghasilkan dunia tunggal (Robertson dalam Sztompka, 2007: 101). Globalisasi memiliki dimensi ideologi dan teknologi. Dimensi teknologi yaitu kapitalisme dan pasar bebas, sedangkan dimensi teknologi adalah teknologi informasi yang telah menyatukan dunia (Friedman, 2005). Globalisasi adalah sebuah proses sosial dimana halangan-halangan bersifat geografis pada tatanan social budaya semakin menyusut dan setiap orang kian sadar bahwa mereka semakin dekat satu sama lain (Waters, 2001). Secara umum globalisasi merupakan sebuah proses dimana ilmu pengetahuan dan teknologi berkembang dengan sangat pesat sehingga dapat merangkul setiap orang kedalam satu dunia yang utuh dan universal.

\section{METODE PENELITIAN}

Penelitian ini menggunakan metode kualitatif, dengan pendekatan fenomenologi untuk menyelidiki hal-hal yang terdapat dalam lingkungan alami (natural settings), dan mencoba menginterpretasi fenomena tersebut. Alat pengumpul data penelitian menggunakan observasi, wawancara, dokumentasi, dan triangulasi. Sumber data primer dalam penelitian ini adalah partisipan dan untuk menambah jumlah partisipan digunakan teknik snowball sampling, yaitu suatu teknik untuk menambah jumlah partisipan dengan meminta kepada partisipan yang telah diwawancarai atau pihak lain yang terkait untuk merekomendasikan (Creswell, 1998). Sedangkan sumber data sekunder diperoleh melalui data-data pendukung yang relevan dengan konteks penelitian. Informasi yang diperoleh peneliti bersumber dari keterangan mengenai permasalahan yang akan diteliti.

\section{HASIL DAN PEMBAHASAN}

\section{- Konsep dan Gagasan Dasar Ilmu Kanuragan Rajah Pakuwon}

Kata Kanuragan dalam bahasa Jawa berarti Ilmu yang memiliki fungsi sebagai alat untuk menjaga atau membela diri secara supranatural, mencakup kemampuan diri untuk bertahan (kebal) terhadap 
berbagai ancaman dan bahaya serta kemampuan menyerang dengan kekuatan luar biasa diluar nalar manusia pada umumnya. Secara garis besar konsep dari Ilmu Kanuragan Rajah Pakuwon adalah suatu ilmu yang memiliki kekuatan magis luar biasa yang dapat digunakan sebagai alat untuk menjaga diri.

Secara historis, Ilmu Kanuragan Rajah Pakuwon tidak dapat dilepaskan dari legenda Prabu Siliwangi dan Pasukan Macan Putih yang melakukan Moksa di wilayah hutan sancang. Sehingga pada gilirannya, ilmu tersebut dikenal juga sebagai ilmu macan putih atau Pamacan Sancang. Moksa berasal dari kata Sansakerta yang digunakan sebagai salah satu konsep agama Hindu dan Buddha, yang mengandung arti Lepas atau kebebasan dari ikatan duniawi dan lepas juga dari putaran reinkarnasi atau purnabawa kehidupan, dengan kata lain moksa merupakan tujuan akhir dalam agama Hindu. Sesuai dengan catatan sejarah, bahwa agama yang dianut oleh Prabu Siliwangi dan pasukannya pada masa itu adalah agama Hindu, yang tidak bersedia masuk Islam dan melarikan diri dari kerajaannya dan pada akhirnya melakukan moksa. Secara garis besar ilmu rajah pakuwon / pamacan sancang merupakan ilmu kekebalan tubuh dari serangan senjata tajam, senjata api maupun serangan yang bersifat magis.

Menurut legenda yang berkembang di masyarakat, pemilik ilmu kanuragan ini akan dapat memiliki kedigjayaan baik selama hidup maupun pada saat meninggal dunia, sebab keistimewaan dari ilmu ini salah satunya adalah munculnya keyakinan bahwa pemilik ilmu akan tetap hidup dalam bentuk lain yakni Macan Putih setelah mengalami kematian.

Ilmu kanuragan Rajah Pakuwon merupakan ilmu kewibawaan yang termasuk dalam kategori ilmu tingkat tinggi dan sangat terkenal dikalangan masyarakat Sunda pada umumnya. Ilmu ini tidak hanya dapat diwariskan dari satu generasi ke generasi berdasarkan ikatan keluarga, namun juga dapat dipelajari dan dimiliki oleh siapa saja yang memiliki ketertarikan terhadap penguasaan ilmu tersebut. Pewarisan ilmu kanuragan dapat dilakukan dengan berbagai cara, adapun bentuk dari ilmu tersebut oleh masyarakat Sancang disebut sebagai Khodam Macan Putih. Kata Khodam sendiri berasal dari bahasa Arab yang artinya pembantu, penjaga atau pengawal. Berdasarkan hal tersebut maka makna dari khodam adalah media yang digunakan manusia untuk membantu atau menjaga mereka dari segala macam bentuk ancaman.

\section{- Karakteristik Perilaku dan Jejak Artefak}

Pemilik Ilmu kanuragan Rajah Pakuwon diyakini akan memperoleh berbagai bentuk kewibawaan yang luar biasa, bahkan tidak jarang mereka yang memiliki ilmu tersebut akan muncul sebagai orang yang sangat disegani dan bahkan dihormati karena kesaktian yang dimiliknya. Pada perkembangannya, pemilik ilmu ini juga dikenal dengan sebutan jawara yang kemudian bertransformasi menjadi pemimpin tradisional dalam struktur sosial. Jawara dimaknai sebagai individu maupun kolektivitas kultural yang mempunyai struktur jaringan organisasi yang berbasis pada bentuk kekeluargaan, keturunan, ilmu silat dan kanuragan, spiritual, kekerasan dan kemampuan dalam mengelola ekonomi, bisnis, dan budaya sehingga berpotensi untuk melakukan penetrasi sosial maupun politik terhadap anggota masyarakat lainnya maupun institusi pemerintah (Bandiyah, 2010). Dalam struktur sosial, jawara dengan kondisi objektif pada masa lalu sebagai pemimpin desa, penjaga keamanan desa, maupun menjadi guru silat dan guru magis (Hudaeri, 2001)

Perilaku tersebut didasarkan pada keyakinan bahwa mereka yang berhasil menguasai ilmu tersebut tidak akan dapat dikalahkan secara mudah oleh lawan dan musuh. Adapun cara yang biasa digunakan untuk memperoleh ilmu tersebut adalah dengan melakukan Puasa Mutih dan Tirakat selama 40 hari. Puasa Mutih adalah berpuasa atau berpantang makan dan minum apa saja kecuali nasi putih dan air putih. Jenis puasa ini biasanya dikenal di lingkungan penganut kejawen dan praktisi supranatural dengan tujuan untuk mendapatkan ilmu gaib, keberhasilan maksud serta tujuan dan lain-lain. Sedangkan yang dimaksud dengan Tirakat adalah melakukan pertapaan atau semedi di sekitar wilayang hutan sancang dengan mengamalkan berbagai bacaan atau jimat yang diberikan oleh guru spiritual nya, dan harus dilakukan selama 40 hari 40 malam tanpa jeda. Seseorang yang 
berhasil melakukan seluruh tata cara yang diharuskan tersebut, kemudian diyakini akan dapat berhasil memasukan ilmu pamacan kedalam jiwa nya. Seseorang yang memiliki ilmu ini diyakini akan berubah menjadi harimau putih setelah wafat, ditandai dengan munculnya cekungan yang cukup besar disebelah makam tempat pemilik ilmu tersebut dikebumikan.

Adapun bentuk jimat yang akan dimiliki oleh seseorang yang telah memperoleh ilmu kanuragan rajah pakuwon ini biasanya adalah batu ali ataupun keris. Berdasarkan hasil wawancara paling tidak diketahui terdapat sedikitnya lima jejak artefak peninggalan Prabu Siliwangi yang diyakini erat kaitannya dengan kamampuan ilmu kanuragan tersebut. Kelima artefak itu adalah (1) Kujang Macan Putih Siliwangi; (2) Pusaka Kujang Alam Gaib; (3) Mustika Dewi Kembang; (4) Mustika Macan Kembar; (5) Keris Naga Runting. Peninggalan berupa artefak tersebut kemudian disimpan dan dijaga oleh pemilik ilmu kanuragan Rajah pakuwon untuk dipergunakan sebagaimana mestinya.

\section{- Transformasi dan Eksistensi Ilmu di era Globalisasi}

Transformasi merupakan perpindahan atau pergeseran suatu hal kearah yang lain atau baru tanpa mengubah struktur yang terkandung didalamnya, meskipun dalam bentuknya yang baru telah mengalami perubahan. Kerangka transformasi budaya adalah struktur dan kultur (Yunus, 2013).

Ilmu kanuragan Rajah Pakuwon memiliki jejak yang cukup panjang dalam perjalanan sejarah masyarakat Sancang Garut. Dikenal sebagai ilmu hikmah yang sangat melegenda, masyarakat Sunda pada umumnya mengenal kejayaan ilmu kanuragan rajah pakuwon sebagai warisan budaya yang patut dilestarikan. Selain untuk kepentingan pewarisan budaya, mereka juga meyakini bahwa mendalami ilmu tersebut dapat memberikan keuntungan tersendiri bagi diri, keluarga, dan masyarakat sekitar yang membutuhkan pertolongan. Keuntungan tersebut berkaitan dengan kekuatan yang dapat digunakan untuk melindungi diri dan bahkan orang lain dari kejahatan atau ancaman yang mungkin akan muncul dan mengganggu keamanan dan keselamatan.

Pada masa lalu, ilmu kanuragan rajah pakuwon memiliki peran yang sangat penting dalam proses pendidikan dari satu generasi ke generasi. Hal ini terutama karena setiap keluarga meyakini bahwa dengan menggunakan ilmu ini dan mewariskannya kepada generasi selanjutnya adalah suatu keharusan untuk menjaga dan mengamankan kehidupan mereka dari situasi kehidupan yang dianggap sangat sulit dan keras. Mereka menganggap bahwa apabila ilmu tersebut tidak dikuasai maka mereka akan menjadi tertindas dan tidak akan dapat melakukan perlawanan terhadap segala bentuk kejahatan dan ketidakadilan. Ilmu kanuragan rajah pakuwon tidak hanya dipelajari oleh para pria, tetapi juga para wanita yang juga diharuskan untuk melindungi diri dan keluarganya. Pada perkembangannya, para pemelihara ilmu ini bertransformasi sebagai jawara. Jawara didefinisikan sebagai pahlawan yang berjuang melawan penjajahan kolonial Belanda dan membela orang-orang yang lemah, they were often involved in actions against government officials (Sartono, 1996:110-111 dalam Ensering, 1995).

Seiring dengan perkembangan zaman di era globalisasi saat ini yang salah satunya ditandai dengan kemajuan teknologi yang semakin canggih turut mempengaruhi cara hidup masyarakat di hampir semua wilayah. Demikian pula dengan masyarakat sekitar hutan sancang saat ini. Berbagai kemudahan mengakses informasi dari kemajuan teknologi yang semakin berkembang turut mempengaruhi pandangan hidup mereka. Hal ini secara langsung berdampak pada menurunnya tingkat kepercayaan terhadap hal-hal yang dianggap tidak logis, termasuk terhadap ilmu kanuragan rajah pakuwon yang syarat dengan nuansa supranatural. Meskipun demikian tidak serta merta ilmu kanuragan ini hilang, beberapa orang masih sangat meyakini bahkan turut melestarikannya melalui pendalaman ilmu tersebut, namun jumlah nya saat ini tidak sebanyak pada masa lalu. Hal tersebut merupakan bagian dari upaya untuk mempertahankan eksistensi ilmu warisan leluhur demi terwujudnya kearifan lokal.

Kearifan lokal yang terdapat dalam budaya lokal yang dijiwai oleh masyarakatnya, namun sejalan dengan perubahan sosial kultural yang demikian cepat, kebudayaan lokal yang yang menyimpan 
kearifan lokal sebagaimana sinyalemen para ahli sebagian telah tergerus oleh kebudayaan global (Smiers, 2009). Budaya globalisasi yang beriringan dengan perkembangan kapitalisme telah menciptakan budaya yang berjarak dengan nilai-nilai kearifan lokal. Dalam hal ini pewarisan ilmu kanuragan rajah pakuwon yang memiliki nilai-nilai adiluhung telah terkontaminasi oleh dinamika perkembangan global. Sehingga dalam perkembangannya ilmu kanuragan rajah pakuwon telah terdegradasi serta hanya menghasilkan output yang artifisial, formalistik, dan ahistoris.

\section{PENUTUP}

Interpretasi objektif jawara rajah sebagai kekuatan budaya masyarakat sancang saat ini tidak terlepas dari kultur sejarah jawara rajah pada masa lalu. Nilai-nilai luhur yang telah berakar dan diwariskan secara turun temurun termanifestasikan dalam budaya lokal yang menjadi ciri khas dan karakter masyarakat setempat. Sejarah ilmu kanuragan rajah pakuwon yang melegenda pada masa lalu yang disertai dengan cerita kepahlawanan, kekuatan, dan hitam putihnya merupakan bagian dari karakteristik yang menandai bahwa Sancang pada masanya pernah memiliki sebuah peradaban sejarah yang dinamis disertai dengan nilai-nilai adiluhung yang kesemuanya harus dihormati, dihargai dan diteladani.

Kemajuan zaman yang semakin berkembang dengan segala macam tantangannya seharusnya tetap dapat memberikan ruang kepada nilai-nilai kearifan lokal agar terjaga eksistensinya. Ilmu Rajah Pakuwon sebagai salah satu dari banyaknya kearifan lokal Sancang memiliki nilai-nilai positif selain dari hal-hal yang kemudian dianggap menyimpang. Nilai positif dari ilmu kanuragan ini adalah sebagai bentuk penjagaan diri dan lingkungan dari ancaman bahaya serta kemampuan manusia untuk menyelaraskan diri dengan alam. Adapun hal-hal yang dianggap menyimpang seperti penyalahgunaan ilmu untuk sesuatu yang tidak baik harus ditinggalkan dan dicari solusi yang tepat. Upaya-upaya tersebut diharapkan akan mampu mendorong keberlangsungan ilmu rajah pakuwon sebagai bagian dari nilai kearifan lokal khas Hutan Sancang.

\section{DAFTAR PUSTAKA}

[1] Creswell, J.W. 1998. Qualitative Inquiry and Research Design: Choosing Among Five Tradition, Qualitative Health Research

[2] Friedman, T.L 2005. It's A Flat the World, After All. New York Time Magazine. April 3, 2005.

[3] Giddens, Anthony (1991) Modernity and Self-Identity. Self and Society in the Late Modern Age. Cambridge: Polity (publisher)

[4] Hudaeri, Muhammad. 2001. Tasbih dan Golok (Studi Kharisma Kyai dan Jawara di Banten). Serang Banten: STAIN

[5] Sedyawati, Edy. 2006. Budaya Indonesia (Kajian Arkeologi, Seni, dan Sejarah). Jakarta: PT. Raja Grafindo Persada.

[6] Smiers, Jost. 2009. Art Under Prusser. Memperjuangkan Keanekaragaman Budaya di Era Globalisasi. Terjemahan Umi Haryati. Yogjakarta : Insist Press

[7] Sztompka, Piotr. 2007. Sosiologi perubahan sosial. Jakarta : Prenada

[8] Syarbaini. Syahrial. 2014. Pendidikan Pancasila di Perguruan Tinggi (Implementasi Nilai-nilai Karakter Bangsa). Jakarta: Ghalia Indonesia.

[9] Waters, M. 1995. Globalization. 2nd Edition. Taylor and Francis Group. London.

[10] Wibowo, A dkk. 2015. Pendidikan Karakter Berbasis Kearifan Lokal di Sekolah. Yogjakarta: Pustaka Pelajar

[11] Alfian, Magdalia. (2013). "Potensi Kearifan lokal dalam Pembentukan Jati Diri dan Karakter Bangsa". Prosiding The 5 thn ICSSIS; "Ethnicity and Globalization", di Jogyakarta pada tanggal 13-14 Juni 2013.

[12] Bandiyah. 2010. Evolusi Jawara di Banten (Studi Evolusi dari Bandit menjadi Jawara). Jurnal Interaktif Universitas Brawijaya. Vol 1, No.2,pp.111 
p-ISSN : 2655-7304

e-ISSN : 2655-8963

[13] Ensering, Else. 1995. Banten in Times of Revolution, In: Archipel, volume 50, 1995. Banten Histoire d'une region.pp. 131-163

[14] Fajarini,Ulfah. 2014. "Peranan Kearifan Lokal Dalam Pendidikan Karakter". Jurnal Sosio Didaktika; Vol.1, No.2. (http://journal.uinjkt,ac,id/SOSIOFITK/article/viewFile/1225/1093)

[15] Geertz. 2007. "Local Wisdom in Education". Journal of Education. .http://www. ied.edu.hk/cric/

[16] Istiawati, Novia Fitri. (2016). Pendidikan karakter berbasis niali-nilai kearifan local adat ammatoa dalam menumbuhkan karakter konservasi. e-ISSN. 10 (1). Hlm 1- 17

[17] Yunus, Rasid. 2013. Transformasi Nilai-nilai Budaya Lokal Sebagai Upaya Pembangunan Karakter Bangsa : Jurnal Penelitian Pendidikan UPI 